\title{
The potential impact of COVID-19 on the Canadian Resident Matching Service: Unique future challenges faced by urology residency programs and applicants
}

\author{
Uday Mann, MD; Jasmir G. Nayak, MD, FRCSC \\ Section of Urology, Department of Surgery, University of Manitoba, Winnipeg, MB, Canada
}

Cite as: Can Urol Assoc J 2020;14(5):E167-8. htrp://dx.doi.org/10.5489/cuai.6616

$\mathrm{T}$ he World Health Organization declared the COVID19 outbreak a pandemic on March 11, 2020. ${ }^{1}$ Since then, significant measures have been taken by organizations around the world to respond to the ongoing health crisis. Specifically, The Association of Faculties of Medicine of Canada (AFMC) announced on March 20, 2020 that the undergraduate medical education (UME) deans across Canada have decided to suspend new visiting elective applications until further notice due to the COVID-19 pandemic. $^{2}$ Additionally, all medical schools in Canada have suspended clerkships for students indefinitely. Given the uncertainty of the timeline surrounding COVID-19, currently, UME offices are not planning for the return of students to clerkship until mid-June 2020 at the earliest (email communication to UME students). In addition, there are ongoing talks between the UME deans that elective rotations may be cancelled in order to ensure that students complete their core clerkship and start residency by July 1,2021 . This decision would undoubtedly have significant impact on the Canadian Resident Matching Service (CaRMS) applications for these students and specifically for the field of urology in Canada.

Gabrielson et al have recently authored an article that outlines the American urological perspective and raised question regarding whether residency program committees will have to prioritize other measures, such as U.S. Medical Licensing Exams (USMLE) scores in the absence of elective rotations. ${ }^{3}$ In Canada, however, objective measures of academic success are not possible because schools use a pass-fail grading system and most students do not write the USMLE exams. Additionally, studies in urology and other fields have demonstrated that the selection process for residency differs between the U.S. and Canada. ${ }^{4-7}$

In the U.S., USMLE scores and reference letters were ranked as the most important factors for residency applicant selection by urology residency program directors. ${ }^{6}$ This is in contrast with Canadian urology programs; Nguyen et al determined that the three most important aspects of the CaRMS application from the urology residency program's perspective were rotation performance at a specific school, quality of reference letters from urologists, and the interview performance. ${ }^{7}$ In Canada, clinical performance during elective rotations at specific schools is heavily prioritized by residency programs when selecting and ranking applicants for the CaRMS process. ${ }^{7}$ In fact, in the last two years, of the 61 total successful applicants to urology, only one matched without completing an elective in urology in their matched school. ${ }^{8}$ If elective rotations are to be cancelled in order to prioritize core clerkship, urology residency programs will have to rely on other methods to compare applicants and forego prioritizing elective performance. In the absence of other objective measures, programs may rely on undergraduate performance, research, volunteerism, core clerkship performance, and interview performance.

Beyond limiting the means in which a program evaluates prospective urology trainees, the students themselves will be unable to explore centers other than their own home school. Nguyen et al astutely noted that, "...though all residency programs across Canada provide excellent urological training, there are slight variations in education style, institutional objectives, faculty phenotype, and clinical volume/exposure/ practice patterns that result in better or worse fits for different trainees.." ${ }^{\prime 9}$ As much as elective rotations allow residency programs to assess prospective students, they also allow students to assess different programs and determine which programs might suit their own career goals, geographic preferences, and subjective "fit" for themselves. In the absence of elective rotations, students have previously elected to do informal site visits, but with increasing travel restrictions in the face of COVID-19, these informal site visits may also be limited. Additionally, students from medical schools without urology residency programs may have an additional disadvantage, as they would have fewer networking opportunities during clerkship compared to students who have urology residency programs at their own institutions. If students are unable to form their own personal opinions about the various residency programs across Canada, they are likely to face difficulties when they create their CaRMS rank list. 
Traditionally, residency applicants travel from city to city interviewing for residency spots during CaRMS interview period. Urology in Canada is unique because it is the only specialty that offers applicants a single-site, single-day fair to conduct residency application interviews. This day, known as the "Canadian Urology Fair," has been ongoing since 1994, when it was created to ease the financial burden for applicants and to minimize time away from medical training. ${ }^{10}$ Unfortunately, this advancement may become a hindrance, as the traditional model of travelling from city to city allows applicants to explore the facilities/resources each program offers, but the single-site approach would inherently not permit this. Additionally, it is unclear whether in-person interviews will be feasible in the face of COVID-19, or whether programs will have to conduct virtual interviews with applicants.

Perhaps the most significant effect of medical students losing elective time will be the decreased exposure to the field of urology. Of the 17 medical schools in Canada, only one offers a mandatory urology clerkship rotation. The remainder of the schools offer a selective rotation in urology, with only $25 \%$ of medical students completing this selective rotation. ${ }^{9}$ Patel et al studied the effects of a mandatory urology rotation and found that students who had a mandatory urology clerkship felt more comfortable with common urological problems, gained a better understanding of urological procedures, and were more likely to consider a career in urology compared to students who did not have a mandatory urology clerkship. ${ }^{11}$

Recently, the AFMC introduced a policy to limit the number of electives that students may undertake in one discipline, with the aim being to ensure a well-rounded medical education, as well as to permit consideration of multiple career options. ${ }^{12}$ Though this policy may adversely affect students who develop an early interest in urology as a career, it may also permit students to complete electives in disciplines they might not have previously considered - including the conversion of non-urology students to urology all-stars. In other words, these changes may allow students who discover urology as a potential career later in medical school to still complete electives in urology and competitively apply to urology residency. As seen by the results of a survey completed by American Association of Medical Colleges (AAMC), of the 187 students who expressed interest in urology as their preferred career at the end of medical school in 2019, only 4\% indicated they wanted urology as their preferred career at the beginning of medical school. ${ }^{13}$ These findings suggest that the conversion happens during their undergraduate medical education, including during elective periods. Provided that very few Canadian medical students are exposed to urology via core clerkship, the amount of exposure to urology may be significantly impacted by the cancellation of elective rotations in the face of COVID-19, and thus limit potential applications to urology.

The COVID-19 pandemic has had significant global impact, and medical training is no exception. Though the necessary limitations in undergraduate medical education are likely to affect all specialties, the field of urology is likely to be disproportionately affected due to the absence of urology exposure at most Canadian medical schools. As many students will not have had any exposure to clinical urology, there may be a decreased interest in the field for upcoming residency applications. Additionally, both residency programs and applicants may encounter difficulties when determining their rank lists in the absence of elective rotations. Prospective students to urology residency programs may be most inclined to focus on urological research to express interest in the specialty with continued excellence in core clerkship to ensure top letters of recommendation in support of their CaRMS application. Lastly, Canadian urology residency programs may need to consider novel methods to showcase their programs in the upcoming academic year.

Competing interests: The authors report no competing personal or financial interests related to this work.

This paper has been peer-reviewed.

\section{References}

1. World Health Organization. Coronavirus disease (COVID-19) Pandemic. Available at: www.who.intemergenciesdiseasesnovel-coronavirus. Accessed April 9, 2020.

2. The Association of Faculties of Medicine of Canada. COVID-19. Available at: https://afmc.ca/priorities/ covid 19. Accessed April 9, 2020

3. Gabrielson AT, Kohn TP, Clifton MM. COVID-19 and the urology match: Perspectives and a call to action. J Urol 2020. [Epub ahead of print]. https://doi.org/10.1097/JU.0000000000001037

4. Krauss EM, Bezuhly M, Williams JG. Selecting the best and brightest: A comparison of residency match processes in the United States and Canada. Plast Surg 2015;23:225-30. https://doi.org/10.1177/229255031502300410

5. Eneh AA, Jagan L, Baxter S. Relative importance of the components of the Canadian Residency Matching Service application. Can J Ophthalmol 2014;49:407-13. https://doi.org/10.1016/i.icio.2014.06.009

6. Weissbart SJ, Stock JA, Wein AJ. Program directors' criteria for selection into urology residency. Urology 2015;85:731-6. https://doi.org/10.1016/i.urology.2014.12.041

7. Nguyen D-D, Lee JY, Domes T, et al. Survey of Canadian urology programs: Which aspects of the Canadian Residency Matching Service (CaRMS) application are the most important? Can Urol Assoc J 2020 January 20; Epub ahead of print. https://doi.org/10.5489/cuaj.619]

8. The Canadian Resident Matching Service. R-1 match electives data. Available at: www.carms.ca. Accessed April 9, 2020

9. Nguyen D-D, Lee JY, Couture F, et al. The AFMC electives diversification policy: Potential drawbacks and benefits for medical students applying to urology. Can Urol Assoc J 2019;13:427-9. https://doi.org/10.5489/cuai.6000

10. Grober ED, Matsumoto ED, Jewett MAS, et al. The Canadian urology fair: A model for minimizing the financial and academic costs of the residency selection process. Can I Surg 2003;46:458-62.

11. Patel P, Nayak JG, MGGregor TB. The value of a core clinical rotation in urology for medical students. Can Urol Assoc J 2015;9:392-5. htrps://doi.org/10.5489/cuai.3297

12. The Association of Faculties of Medicine of Canada. AFMC student electives diversification policy. Available at: htrps://afmc.ca/en/media-releases/afmc-student-electives-diversification-policy. Accessed April 9, 2020.

13. American Association of Medical Colleges. 2019 report on residents. Available at: htrps://www.aamc. org/data-reports/students-residents/interactive-data/report-residents/2019/table-al-continuity-specialtypreference-matriculating-student-questionnaire. Accessed April 9, 2020.

Correspondence: Dr. Jay Nayak, St. Boniface Hospital, Winnipeg, MB, Canada; jnayak@sbgh.mb.caz 